\title{
STUDI OKSIDASI PADUAN BAJA Fe-Cr-ZrO 2 DENGAN METODE SINTESIS HIGH ENERGY MILLING DAN ULTRASONIC MENGGUNAKAN THERMOGRAVIMETRI
}

\section{STUDY OF OXIDATION OF Fe-Cr-ZrO ${ }_{2}$ ALLOY USING HIGH ENERGY MILLING AND ULTRASONIC METHOD USING THERMOGRAVIMETRY}

\author{
Rohmad Salam*, Nanda Shabrina, Bernandus Bandriyana \\ Pusat Sains dan Teknologi Bahan Maju, PSTBM-BATAN, Puspiptek, Indonesia \\ E-mail penulis pertama: salam_rd@yahoo.com
}

Diterima 5 Agustus 2020, diterima dalam bentuk perbaikan 4 Januari 2021, disetujui 7 Juni 2021

\begin{abstract}
ABSTRAK
STUDI OKSIDASI PADUAN BAJA Fe-Cr-ZrO ${ }_{2}$ DENGAN METODE SINTESIS HIGH ENERGY MILLING DAN ULTRASONIC MENGGUNAKAN THERMOGRAVIMETRI. Telah dilakukan uji thermogravimetri untuk mempelajari perilaku oksidasi paduan baja komponen suhu tinggi $\mathrm{Fe}-\mathrm{Cr}-\mathrm{ZrO}_{2}$ sebagai aplikasinya pada komponen temperatur suhu tinggi. Penelitian ini mempelajari mengenai efek chromium pada paduan yakni $20 \mathrm{Cr}$ dan $25 \mathrm{Cr}$ (persen berat) serta perbandingan metode sintesisnya yang menggunakan metode High Energy Milling (HEM) dan metode sonochemistry ultrasonik selama masing-masing 20 jam. Uji oksidasi dilakukan dengan Magnetic Suspension Balance (MSB) pada suhu $700{ }^{\circ} \mathrm{C}$ selama 400 menit. Pengujian Scanning Electron Microscopy-Energy Dispersive X-Ray Spectroscope (SEM-EDS) dilakukan untuk menganalisa ketebalan lapisan oksida yang terbentuk beserta kandungan lapisan oksidanya. Didapatkan bahwa paduan dengan $25 \mathrm{Cr}$ memiliki lapisan oksida yang lebih rendah dibandingkan dengan $20 \mathrm{Cr}$. Perbedaan metode sintesis juga memiliki pengaruh terhadap lapisan oksida yang terbentuk. Didapatkan bahwa lapisan oksida paduan dengan metode sintesis menggunakan metode ultrasonik memiliki pertambahan massa yang lebih besar dibandingkan sintesis menggunakan metode HEM. Selain itu, kandungan $\mathrm{O}$ dan $\mathrm{C}$ yang terbentuk lebih banyak dibanding paduan dengan sintesis HEM. Hasil pengujian X-Ray Difraction (XRD) didapatkan fasa oksida $\mathrm{Cr}_{2} \mathrm{O}_{3}$ selain fasa utama $\mathrm{Fe}$.
\end{abstract}

Kata kunci: MSB, paduan Fe-Cr-ZrO2, Oksidasi, HEM, Ultrasonik.

\section{ABSTRACT}

STUDY OF OXIDATION OF Fe-Cr-ZrO ${ }_{2}$ ALLOY USING HIGH ENERGY MILLING AND ULTRASONIC METHOD USING THERMOGRAVIMETRY. Thermogravimetric tests have been carried out to study the oxidation behavior of high-temperature steel $\mathrm{Fe}-\mathrm{Cr}-\mathrm{ZrO}_{2}$ as its application as high temperature components. This paper studied about the effects of chromium precentage in $\mathrm{Fe}-\mathrm{Cr}-\mathrm{ZrO}$ alloys with $20 \mathrm{Cr}$ and $25 \mathrm{Cr}$ are prepared using High Energy Milling (HEM) method and the ultrasonic sonochemistry method for 20 hours. The thermogravimetric test was carried out with Magnetic Suspension Balance (MSB) at a temperature of $700^{\circ} \mathrm{C}$ for 400 minutes. Scanning Electron MicroscopyEnergy Dispersive X-Ray Spectroscope (SEM-EDS) are used to analyze the thickness and element content of the oxide layer. It was found that the alloy with $25 \mathrm{Cr}$ had a lower oxide layer compared to the $20 \mathrm{Cr}$ alloy. The different synthesis methods also influenced the oxide layer. It was found that the alloy oxide layer prepared by the ultrasonic sonochemistry synthesis method had a heigher mass-gain than the alloy prepared by the HEM method. In addition, the contents of $\mathrm{O}$ and $\mathrm{C}$ in the alloy prepared by the ultrasonic sonochemistry method is higher than in alloys prepared by the HEM method synthesis. $X$-Ray Difraction (XRD) analysis showed $\mathrm{Cr}_{2} \mathrm{O}_{3}$ phase beside $\mathrm{Fe}$ phase.

Keywords: MSB, Fe-Cr-ZrO 2 alloy, Oxidation, HEM, Ultrasonic 
Jurnal Iptek Nuklir Ganendra

Ganendra Journal of Nuclear Science and Technology

Vol. 21 No.2, Juli-2021: 51-57

\section{PENDAHULUAN}

Daduan Fe-Cr merupakan bahan dasar pembuatan baja karena sifatnya diantaranya yaitu suhu ductile to brittle transition yang rendah, ketahanan terhadap swelling, dan ketahanan tempertur tinggi. Baja berbasis feritik/martensitic Fe-Cr dianggap sebagai kandidat yang baik untuk desain berbagai komponen struktural dalam instalasi energi nuklir canggih seperti Generasi IV dan reaktor fusi [1]. Penambahan oksida lain pada paduan $\mathrm{Fe}-\mathrm{Cr}$ dalam bentuk ODS (Oxide Dispersed Steel) meningkatkan ketahanan korosi pada kondisi ekstrim. Banyak penelitian menggunakan oksida $\mathrm{ZrO}_{2}$ dan $\mathrm{Y}_{2} \mathrm{O}_{3}$ sebagai ODS pada paduan $\mathrm{Fe}-\mathrm{Cr}$. Beberapa penulis melaporkan bahwa penambahan oksida berkontribusi pada ketahanan korosi tinggi yang disebabkan oleh homogenitas kimia dan pembentukan lapisan pasif kaya kromium secara cepat [2]. Laporan lain menyebutkan bahwa fase $\beta(\mathrm{Fe}, \mathrm{Cr}, \mathrm{Zr})$ dan fase intermetalik $(\mathrm{Fe}, \mathrm{Cr})_{2} \mathrm{Zr}$ yang terdapat pada paduan Fe-Cr-Zr kaya Fe menunjukkan kombinasi kekuatan dan keuletan yang baik di temperatur ruangan [3].

Aplikasi ODS banyak dimanfaatkan sebagai bahan struktur pada aplikasi teknologi nuklir karena sifatnya yang stabil pada temperatur tinggi dan ketahanan iradiasi pada temperatur tinggi. Sehingga berpotensi menjadi kandidat utama untuk material fuel cladding [4,5]. Oksida pada ODS berperan sebagai presipitasi yang menjadi sumber utama penambahan kekuatan di temperatur tinggi pada fasa feritik dan martensit $[5,6]$.

Fabrikasi ODS banyak menggunakan metode paduan mekanik serbuk (powder mechanical alloying) seperti menggunakan ball mill HEM (High Energy Milling) [6,7]. Metode ini sangat sederhana yakni mencampur paduan dengan menggunakan energi dari reaksi tumbukan antara paduan dan bola-bola milling dalam suatu jar. Meskipun sederhana, banyak parameter yang perlu dikontrol seperti BPR (ball to powder ratio), lama milling, kecepatan milling dan lainnya. Metode lain yang juga banyak digunakan untuk memfabrikasi ODS adalah dengan menggunakan metode ultrasonik [8,9]. Dilaporkan bahwa metode ini dapat mensintesis paduan mikro dalam baja dengan mudah dan efisien. Metode ini menggunakan larutan toluene sebagai media terbentuknya kavitasi. Kavitasi yang terbentuk dari gelombang ultrasonik berintensitas tinggi yang menghasilkan gelembung-gelembung berenergi tinggi yang mendorong terjadinya eksplosi besar yang dapat memadukan paduan didalamnya [8]. Hasil paduan tersebut kemudian disinter menggunakan Arc Plasma Sintering (APS) yang merupakan pembaruan pada metode sintering yang menggunakan plasma untuk proses sinteringnya $[10,11]$.

Salah satu masalah kritis untuk material suhu tinggi adalah terjadinya peningkatan korosi khususnya oksidasi yang menyebabkan penurunan kekuatan material. Unjuk kerja ketahanan oksidasi ini dapat diamati salah satunya dengan pengujian menggunakan Magnetic Suspention Balance (MSB) yang merupakan thermogravimetri yang bekerja berdasarkan perubahan massa ketika sampel mengalami pemanasan yang menggunakan prinsip keseimbangan suspense magnetik [12,13]. MSB dapat mengukur laju oksidasi dengan menyajikan kurva penambahan massa (mass gain) sebagai fungsi waktu untuk suatu pengujian pada temperatur tertentu.

Dalam penelitian ini disajikan hasil analisis performa oksidasi ODS Fe-Cr dengan presentase $25 \mathrm{Cr}$ dan $20 \mathrm{Cr}$ dengan masing-masing menggunakan oksida $\mathrm{ZrO}_{2}$ serta metode fabrikasinya masing-masing menggunakan metode HEM dan Ultrasonik serta menggunakan metode APS sebagai sinteringnya. Fokus penelitian pada kinetika proses oksidasi bahan paduan tersebut seperti pembentukan oksida dan laju oksidasi serta proses spaling lapisan oksida ketika bahan berada pada kondisi temperatur tinggi dalam lingkungan udara atmosfir.

\section{METODOLOGI}

Material yang digunakan dalam penelitian ini adalah $\mathrm{Fe}-20 \mathrm{Cr}-\mathrm{ZrO}_{2}$ dan $\mathrm{Fe}-25 \mathrm{Cr}-\mathrm{ZrO}_{2}$ dengan komposisi disajikan pada Tabel 1. 
Studi Oksidasi Paduan Baja Fe-Cr-ZrO2 Dengan Metode Sintesis

High Energy Milling Dan Ultrasonic Menggunakan TherMogravimetri

(Rohmad Salam, dkk.)

Tabel 1. Komposisi paduan $\mathrm{Fe}-\mathrm{Cr}-\mathrm{ZrO}_{2}$.

\begin{tabular}{lllllll}
\hline No & $\begin{array}{l}\text { Nama } \\
\text { Sampel }\end{array}$ & Komposisi & $\begin{array}{l}\mathrm{Cr} \\
(\% \text { massa })\end{array}$ & $\begin{array}{l}\mathrm{ZrO}_{2} \\
(\% \text { massa })\end{array}$ & $\begin{array}{l}\mathrm{Fe} \\
(\% \text { massa })\end{array}$ & Metode \\
\hline $\mathbf{1}$ & Sampel A & $\mathrm{Fe}-25 \mathrm{Cr}-\mathrm{ZrO}_{2}$ & 25 & 0.5 & Balance & Ultrasonik 20 jam \\
2 & Sampel B & $\mathrm{Fe}-20 \mathrm{Cr}-\mathrm{ZrO}_{2}$ & 20 & 0.5 & Balance & Ultrasonik 20 jam \\
3 & Sampel C & $\mathrm{Fe}-20 \mathrm{Cr}-\mathrm{ZrO}_{2}$ & 20 & 0.5 & Balance & HEM 20 jam \\
\hline
\end{tabular}

Ketiga sampel dibuat dengan komposisi tertentu seperti yang tertulis pada Tabel 1, kemudian sampel disinter dengan APS pada 80A selama 4 menit [11]. Sampel kemudian dipress dalam bentuk ring dengan diameter luar $20 \mathrm{~mm}$, diameter dalam $10 \mathrm{~mm}$ dan ketebalan $2 \mathrm{~mm}$, dengan tekanan 20 Ton selama 3 menit yang sebelumnya divibrasi terlebih dahulu selama 2 menit menghindari adanya ruang-ruang yang berpotensi menjadi pori saat terjadi pressing.

Setelah sintering sampel digrinda dengan kekasaran 400, 800 hingga 2000 grit. Sampel kemudian dikarakterisasi dengan mikroskop optik, Scanning Electron Microscopy- Energy Dispersive X-Ray Spectroscope (SEM-EDS), X-Ray Difraction (XRD) untuk menganalisa struktur mikro dan fasa. Karakterisasi XRD menggunakan radiasi $\mathrm{CuK}_{\mathrm{a}}$ dengan rentang pengukuran $2 \theta=10-90^{\circ}$ dengan step size $0.02^{\circ}$. Pengamatan tampang lintang (cross section) dilakukan dengan mounting sampel. Pengujian MSB dilakukan untuk melihat performa oksidasi pada suhu $700^{\circ} \mathrm{C}$. Pengukuran luas permukaan dilakukan sebelum dilakukan uji MSB.

\section{HASIL DAN PEMBAHASAN}

Kurva oksidasi paduan Fe-Cr- $\mathrm{ZrO}_{2}$ dengan masing-masing karakteristik yang tertuang pada Tabel 1 ditunjukan pada Gambar 1, yakni pertambahan massa akibat oksidasi lingkungan udara pada suhu 700 ${ }^{\circ} \mathrm{C}$ selama 400 menit. Dapat dilihat pada kurva tersebut bahwa ketiga polanya tampak seperti mengikuti kinetika pertumbuhan oksida parabola dimana pertambahan berat sebanding dengan akar kuadrat dari waktu. Sampel A dan B adalah paduan berbasis $\mathrm{Fe}-\mathrm{Cr}-\mathrm{ZrO}_{2}$ dengan metode pembuatan ultrasonik dengan sampel A memiliki persentase $\mathrm{Cr}$ lebih banyak daripada sampel $\mathrm{B}$ yakni $25 \mathrm{Cr}$ dan $20 \mathrm{Cr}$. Terlihat perbedaan bahwa pertambahan massa oksida sampel B lebih besar dibandingkan dengan sampel A. Penambahan presentase $\mathrm{Cr}$ membuat lapisan oksida yang terbentuk pada paduan ini lebih kecil. Mekanisme oksidasi suhu tinggi paduan $\mathrm{FeCrZrO}$ secara luas diterima menjadi difusi anion oksigen melalui kisi $\mathrm{ZrO}_{2}$ dan kation logam transportasi namun sepenuhnya terhambat [12]. Disamping itu, kurva oksidasi sampel A terlihat adanya penurunan massa per satuan luas yang cukup tajam pada waktu oksidasi 60 menit. Fenomena ini disebabkan adanya pertumbuhan yang kemudian disusul oleh pengelupasan (flaking) lapisan oksida secara lokal. Adanya fenomena pengelupasan lapisan oksida secara lokal pada sampel A, diasumsikan karena adanya jumlah pengotor yang lebih banyak dibandingkan dengan sampel lainnya. Adanya pengotor akan menghasilkan defect (cacat) lebih banyak sehingga kemungkinkan terjadinya pengelupasan lapisan akan semakin besar [14].

Perbedaan metode sintesis paduan $\mathrm{Fe}-20 \mathrm{Cr}-\mathrm{ZrO}_{2}$ juga mempengaruhi pertumbuhan oksida pada paduan ini. Terlihat bahwa paduan dengan metode sintesis menggunakan metode ultrasonik memiliki pertambahan massa per satuan luas $(\Delta \mathrm{m} / \mathrm{A})$ yang lebih besar dibandingkan sintesis menggunakan metode HEM. Metode ultrasonik dapat meningkatkan kristalinitas dan menurunkan ukuran partikel sehingga butirbutir yang terbentuk akan semakin kecil dan banyak. Dengan demikian, batas butir yang terbentuk akan semakin luas sehingga menjadikan tempat tempat oksida yang tumbuh akan semakin banyak sehingga pertumbuhan oksida yang terbentuk akan semakin banyak pula. Pengamatan SEM EDS dilakukan selanjutnya untuk mengetahui mikrosturktur lapisan oksida dan jenis lapisan oksida yang terbentuk. 


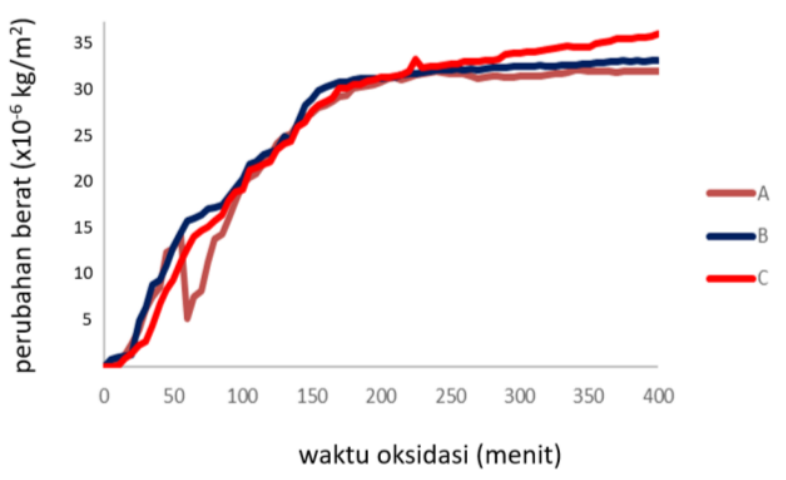

Gambar 1. Kurva oksidasi paduan $\mathrm{Fe}-\mathrm{Cr}-\mathrm{ZrO}_{2}$ pada suhu $700^{\circ} \mathrm{C}$ selama 400 menit.

Gambar 2 menunjukkan hasil analisa SEM dan spektrum EDS yang didapat dari sampel setelah pengujian MSB. Terlihat pertumbuhan oksida pada sampel $A$ dan $C$ cenderung tidak teratur jika dibandingkan dengan sampel $B$, yang mengindikasikan bahwa pertumbuhan oksida pada sampel $A$ dan $C$ terjadi ke dalam. Lapisan oksida pada sampel $A$ terlihat lebih tinggi dibandingkan yang lainnya dan memiliki pori yang cukup banyak. Sedangkan lapisan oksida pada sampel $B$ terlihat lebih terstruktur dan lebih padat dengan kontras yang cukup jelas. Ketinggian lapisan oksida baik pada sampel $A, B$ dan $C$ bervariasi mulai dari 5,2 $\mu \mathrm{m}$ hingga 19,2 $\mu \mathrm{m}$. Hasil EDS terverifikasi pada Gambar 2 dengan perhitungan berdasarkan CliftLorimer rasio dan pada Tabel 2 yang menyatakan kandungan oksida dalam persen massa yang terbentuk pada paduan.
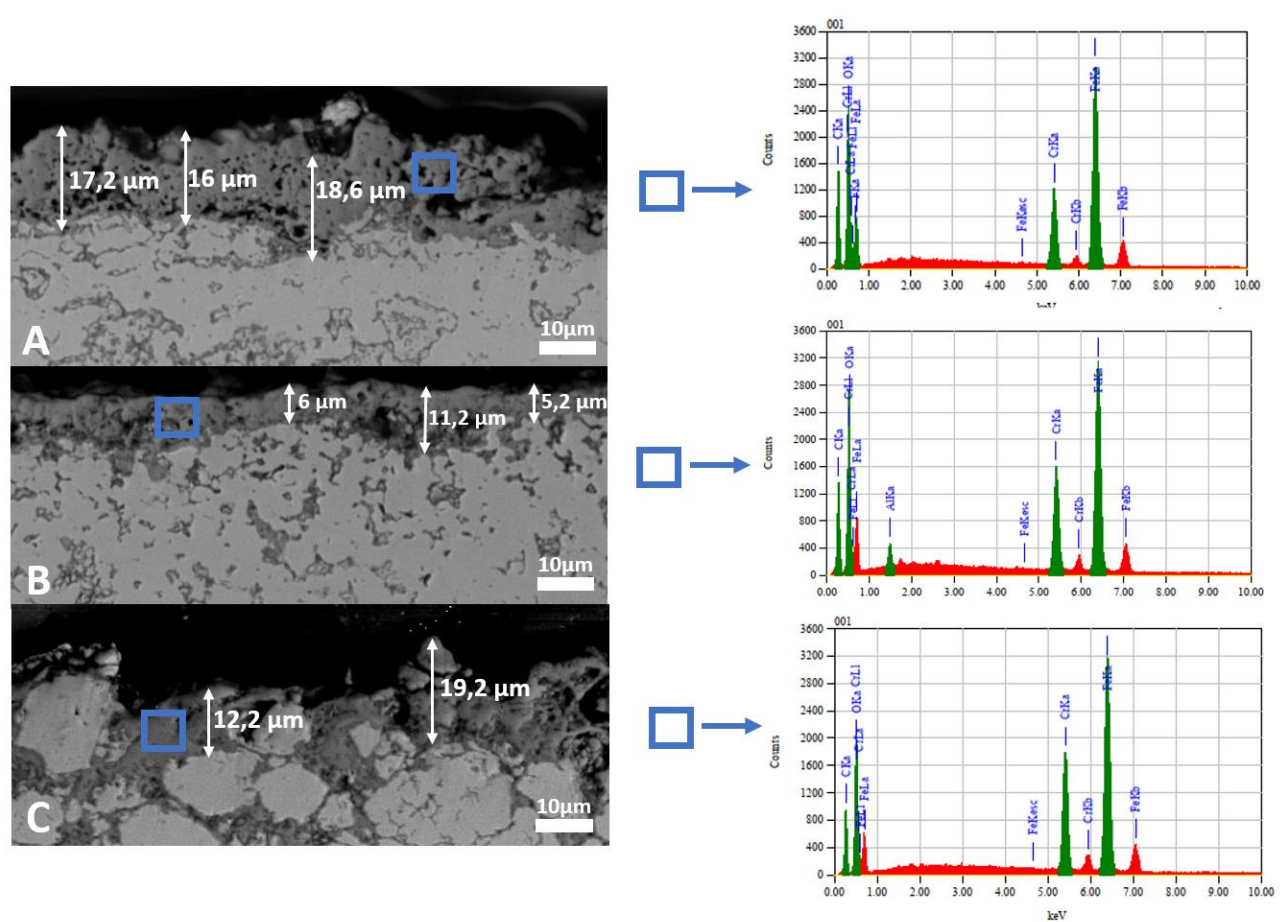

Gambar 2. SEM dan EDS Paduan Fe-Cr-ZrO 2 sampel A, B dan C. 
Studi Oksidasi Paduan Baja Fe-Cr-ZrO2 Dengan Metode Sintesis High Energy Milling Dan Ultrasonic Menggunakan TherMogravimetri (Rohmad Salam, dkk.)

Tabel 2. Kandungan elemen hasil EDS Paduan Fe-Cr-ZrO .

\begin{tabular}{llllll}
\hline & Fe (\%massa) & Cr (\%massa) & O (\%massa) & C (\%massa) & $\begin{array}{l}\text { Pengotor } \\
\text { Elemen lain } \\
(\% \text { massa) }\end{array}$ \\
\hline Sampel A & 42,81 & 9,71 & 23 & 21,61 & $\mathrm{~F}(2.87)$ \\
Sampel B & 43,27 & 12,66 & 23,5 & 19,18 & $\mathrm{Al}(1.39)$ \\
Sampel C & 50,09 & 16,43 & 17,44 & 16,04 & - \\
\hline
\end{tabular}

Dari hasil EDS pada Tabel 2, kemungkinan oksida yang terbentuk adalah besi oksida dan kromium oksida. Sampel B memiliki kandungan oksigen yang lebih besar dibandingkan dengan sampel $A$ dan $C$, hal ini mengindikasikan bahwa terdapat banyaknya jumlah oksida kristalit yang terbentuk yang memungkinkan banyaknya terjadi difusi oksigen menyalurkan antara butir oksida. Hasil ini terkonfirmasi pada Gambar 1 kurva oksidasi paduan, dimana proses sintesis sampel B yang menggunakan metode ultrasonik dimana adanya penurunan ukuran butir dan meningkatan area batas butir, sehingga pertumbuhan oksida yang terbentuk akan semakin banyak. Adapun munculnya unsur karbon pada hasil EDS kemungkinan besar berasal dari resin mengingat pengamatan tampang lintang dilakukan dengan me-mounting sampel menggunakan resin.

Namun kekurangan metode ini adalah adanya pengotor lain yang hadir seperti yang ditunjukkan pada hasil EDS sampel A dan B, yang ditemukan adanya elemen lain seperti $F$ dan Al. Penyebabnya dikarenakan kurangnya kebersihan saat proses terjadi sehingga ada elemen lain yang terperangkap pada ujung probe yang sulit dibersihkan. Hal ini berbeda dengan sampel $C$ yang menggunakan metode HEM, hasil EDS tidak menunjukkan adanya elemen pengotor lainnya.

Pola difraksi sampel A, B dan C pada $20=20^{\circ}$ - $90^{\circ}$ ditunjukkan pada Gambar 3. Pada hasil pola difraksi dianalisa menggunakan program Match!, didapatkan hasil bahwa Fe (\#96-901-3475) merupakan komponen utama semua sampel yang ditunjukkan pada puncak-puncak difraksi pada $2 \theta=44,53^{\circ}(110)$, $2 \theta=64,78^{\circ}(200), 2 \theta=82^{\circ}$ (211). Selain $\mathrm{Fe}$, oksida $\mathrm{Cr}_{2} \mathrm{O}_{3}(\# 96-210-4123)$ terdeteksi pada semua sampel meskipun puncaknya tidak terlalu tinggi, disekitar $2 \theta=22-25^{\circ}$. Selain itu, puncak oksida $\mathrm{Cr}_{2} \mathrm{O}_{3}$ ditemukan juga pada $2 \theta=65^{\circ}$, namun puncak ini berhimpitan dengan puncak Fe. Puncak oksida $\mathrm{Cr}_{2} \mathrm{O}_{3}$ tertinggi terlihat pada sampel $\mathrm{A}$, dikarenakan komposisi awal pembuatannya sampel A memiliki nilai persen massa $\mathrm{Cr}$ lebih tinggi (25\%) jika dibandingkan dengan sampel sampel B dan C (20\%).

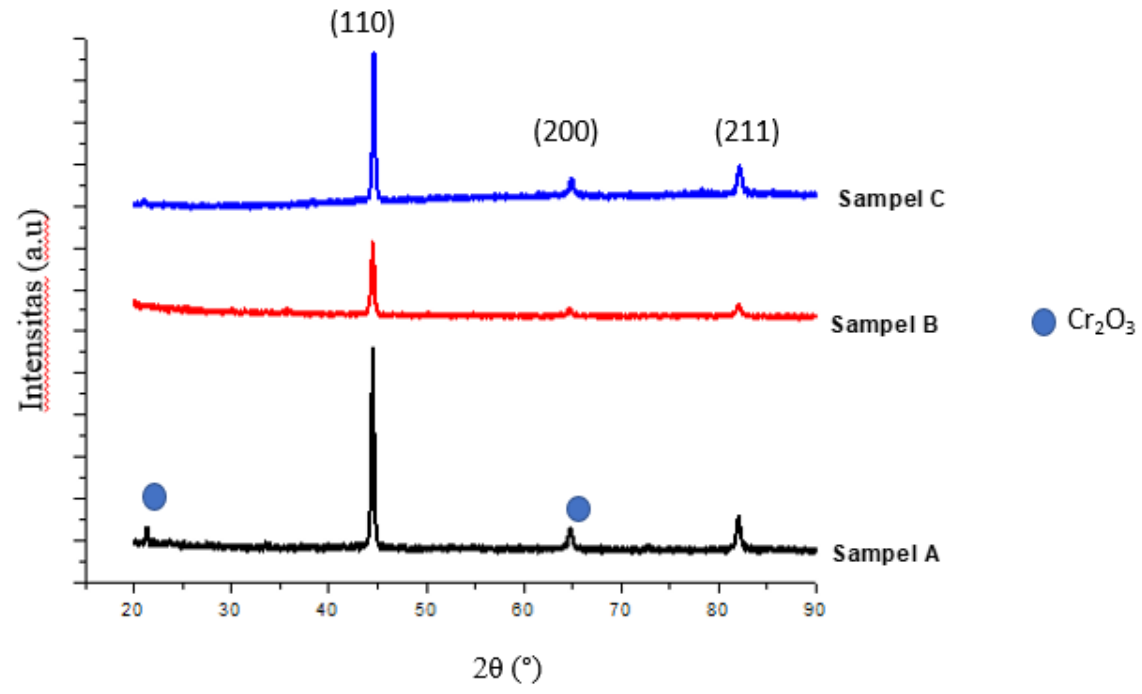

Gambar 3. Pola difraksi sampel A, B dan C. 
Jurnal Iptek Nuklir Ganendra

Ganendra Journal of Nuclear Science and Technology

Vol. 21 No.2, Juli-2021: 51-57

Pada pengujian XRD didapatkan adanya fasa oksida $\mathrm{Cr}_{2} \mathrm{O}_{3}$, sehingga kemungkinan lapisan oksida yang terbentuk adalah lapisan $\mathrm{Cr}_{2} \mathrm{O}_{3}$. Namun demikian, diperlukan penelitian lebih mendalam dengan pengujian Glancing Angle X-ray Diffraction (GAXRD) yang menggunakan sudut kecil 2-5 (small angle) XRD untuk analisa lapisan tipisnya [15].

\section{KESIMPULAN}

Dari pengujian menggunakan MSB, dapat disimpulkan bahwa pertumbuhan lapisan oksida mengikuti laju parabolik. Didapatkan bahwa besar presentase kandungan $\mathrm{Cr}(25 \mathrm{Cr}$ dan $20 \mathrm{Cr}$ ) dan metode sintesisnya memiliki pengaruh terhadap lapisan oksida yang terbentuk pada uji MSB pada suhu $700{ }^{\circ} \mathrm{C}$ selama 400 menit. Selain itu, lapisan oksida paduan dengan metode sintesis menggunakan metode ultrasonik memiliki pertambahan massa yang lebih besar dibandingkan sintesis menggunakan metode $\mathrm{HEM}$. Selain itu, kandungan $\mathrm{O}$ dan $\mathrm{C}$ yang terbentuk lebih banyak dibanding paduan dengan sintesis HEM. Hasil pengujian menggunakan XRD didapatkan fasa oksida $\mathrm{Cr}_{2} \mathrm{O}_{3}$ disamping $\mathrm{Fe}$ sebagai fasa utama.

\section{DAFTAR PUSTAKA}

[1] S. M. Dubiel and J. Żukrowski, "Phase-decomposition-related short-range ordering in a Fe-Cr alloy," Acta Mater., vol. 61, no. 16, pp. 6207-6212, 2013.

[2] M. NAKA, M. Nose, I. OKAMOTO, and Y. ARATA, "Corrosion Behavior of Amorphous Fe-Cr-Zr Alloys," Transactions of JWRI , Technical Notes, vol. 12, 1983.

[3] Y. Yang, L. Tan, H. Bei, and J. T. Busby, "Thermodynamic modeling and experimental study of the Fe-Cr-Zr system," J. Nucl. Mater., vol. 441, no. 1, pp. 190-202, 2013.

[4] T. K. Kim, S. Noh, S. H. Kang, J. J. Park, H. J. Jin, M. K. Lee, J. Jang, C. K. Rhee, "Current Status and Future Prospective of Advanced Radiation Resistant Oxide Dispersion Strengthened Steel (ARROS) Development for Nuclear Reactor System Applications," Nuclear Engineering and Technology, vol. 48, no.2, pp. 572-594, 2016.

[5] B. Gwinner, M. Auroy, D. Mas, A. Saint-Jevin, S. Pasquier-Tilliette, " Impact of the use of the ferritic/martensitic ODS steels cladding on the fuel reprocessing PUREX process," Journal of Nuclear Materials, vol. 428, no. 1-3, pp.110-116, 2012.

[6] A. Zeybek, S. Pirfo Barroso, K. B. Chong, L. Edwards, and M. E. Fitzpatrick, "Incorporation of Y203particles into 410L stainless steel by a powder metallurgy route," J. Mater. Eng. Perform., vol. 23, no. 6, pp. 2120-2130, 2014.

[7] M. Saber, W. Xu, L. Li, Y. Zhu, C. C. Koch, and R. O. Scattergood, "Size effect of primary $\mathrm{Y}_{2} \mathrm{O}_{3}$ additions on the characteristics of the nanostructured ferritic ODS alloys: Comparing as-milled and as-milled/annealed alloys using S/TEM," J. Nucl. Mater., vol. 452, no. 1-3, pp. 223-229, 2014.

[8] M. Silalahi et al., "A New Synthesized Microalloys Steel ODS of High Amplitude Ultrasonically Irradiation," Makara J. Technol., vol. 23, no. 3, pp. 111-118, 2019.

[9] B. Suharno, D. M. Putra, B. Sugeng, T. Hardi, M. Silalahi, "Effect Of Low Amplitude Irradiated Ultrasonic Method Of Characterization Microalloying Fe-Cr- $\mathrm{Y}_{2} \mathrm{O}_{3}$ " International Conference on Earth Sciences and Engineering, 2017.

[10] Bandriyana et al., "Microstructures and Hardness of the High Chromium Oxide Dispersion Strengthened Alloy Fe-25Cr-Y2O3Sintered by the Arc Plasma Sintering (APS)," IOP Conf. Ser. Mater. Sci. Eng., vol. 333, no. 1, 2018.

[11] R. Salam, A. Dimyati, N. Shabrina, and M. Optik, "Pembuatan Baja Oxide Dispersion Strengthened Fe-Cr-Ni Menggunakan Metode Arc Plasma Sintering," J. IIm. Tek. Kim., vol. 4, no. 1, pp. 39-45, 2020. 
Studi Oksidasi Paduan Baja Fe-Cr-ZrO 2 Dengan Metode Sintesis

High Energy Milling Dan Ultrasonic Menggunakan TherMogravimetri

(Rohmad Salam, dkk.)

[12] R. Salam and A. Dimyati, "Uji Fungsi Magnetic Suspension Balance ( MSB ) Untuk Penelitian Material Suhu Tinggi," Seminar Nasional IX SDM Teknologi Nuklir, hal. 242-248, 2013.

[13] Kusdi Prijono, "Uji Ketahanan Korosi pada Temperatur Tinggi $\left(700^{\circ} \mathrm{C}\right)$ dari Logam Paduan Fe-Cr$\mathrm{Y}_{2} \mathrm{O}_{3}$ sebagai Bahan Alternatif Kelongsong (Cladding) Bahan Bakar Nuklir”, Journal of Technical Engineering: Pison vol 2, No 2, pp 32-36, 2019.

[14] Zenja Jefimova. Possible Reasons for Flaking Appearance During Cold Rolling On An Austenitic Stainless Steel. Degree Project In Technology, First Cycle, 15 Credits Stockholm, Sweden, 2016.

[15] Bouroushian, Mirtat, "Characterization of Thin Films by Low Incidence X-Ray Diffraction. Crystal Structure Theory and Applications", Crystal Structure Theory and Applications, vol.1, 35-39, 2012. 